\title{
Kırıkkale ilinde 7-15 yaş grubu çocuklarda arteryel kan basıncı değerlendirilmesi
}

\section{Assessment of arterial blood pressure in children in 7-15 age group in Kırıkkale province}

Cihat ŞANLI', Ayşegül ALPCAN²a

${ }^{1}$ Kıııkkale Üniversitesi Tıp Fakültesi, Çocuk Kardiyoloji Bilim Dalı, Kırıkkale, ${ }^{2}$ ıırıkkale Yüksek Ihtisas Hastanesi, Çocuk Sağlığı ve Hastalıkları, Kırıkkale - TÜRKIYE

\section{ÖZET}

Amaç: Çalışmamız Kırıkkale ilinde ilköğretim çağındaki çocuklarda arteryel kan basıncı ortalamalarının saptanması ve cinsiyet, boy, vücut ağırlığı, vücut kitle indeksi (BMI), yüzey alanı ile ilişkili olup olmadığının değerlendirilmesi amacıyla yapıldı.

Gereç ve Yöntemler: İ merkezinde değişik sosyoekonomik ve kültürel özellikler taşıyan dört ayrı okuldan 7-15 yaş grubunda toplam 905 öğrenci (451 erkek (\%49), 454 kı (\%51)) grup örnekleme yöntemi ile araştırmaya dahil edildi. Her çocuğun arteriyel kan basınçları üçer kez ölçülüp, son ikisinin ortalaması çocuğun kan basıncı olarak kaydedildi, genel fizik incelemesi ve antropometrik ölçümleri yapıldı. Her yaş grubunda sistolik ve diyastolik kan basıncı için 50., 75., 90., 95. persantil değerleri belirlendi. ABD Second Task Force Grubu değerlerine göre sistolik ve diyastolik arteryel kan basıncı değerleri 95. persentil üzerinde olanlar hipertansif olarak kabul edildi.

Bulgular: Buna göre 40 çocukta $(\% 4,4)$ sistolik hipertansiyon (12 erkek, 28 kIz), 28 çocukta $(\% 3,1)$ diyastolik hipertansiyon (6 erkek, 22 kız), $15(\% 1,6)$ çocukta ise hem sistolik hem de diyastolik hipertansiyon (4 erkek, 11 kı) saptandı. Sosyoekonomik düzeyi yüksek okullarda sistolik hipertansiyon oranı \%1,8, diyastolik hipertansiyon oranı \%1,2, sosyoekonomik düzeyi düşük okullarda sistolik hipertansiyon oranı \%2,5, diyastolik hipertansiyon oranı \%1,8 bulunmuştur. Okulların sosyoekonomik durumuna göre, yaş ve cinse bağlı olarak sistolik kan basıncı değerleri arasında anlamlı bir ilişki bulunurken $(p=0,031)$, diyastolik kan basıncı arasında anlamlı bir ilişki $(p=0,086)$ saptanamamıştır.

Sonuç: Her iki cinsiyette de hem sistolik hem de diyastolik arteryel kan basıncı değerleri ile çocuğun yaş, boy, vücut ağılığı, vücut kitle indeksi, yüzey alanı değerleri arasında Pearson Korelasyon Testi ile pozitif ilişki saptanırken, cinsiyet ile anlamlı bir ilişki olmadığı görülmüştür.

Anahtar Kelimeler: Boy, cinsiyet, çocukluk çağı, kan basıncı, vücut ağılığı, 


\section{ABSTRACT}

Aim: The study was conducted to determine average arterial blood pressures in children of elementary school age and assess whether there was any correlation with sex, height, body weight, body mass index (BMI), and surface area.

Material and Methods: Totally 905 students (451male (49\%), 454 female (51\%)) in 7-15 age grup from four different schools with several socioeconomic and cultural characteristics were included in the study by group sampling method. Arterial blood pressures of each children were measured three times, average of the last two measurements were recorded as the blood pressure of the child, and general physical examinations and antropometric measurements were performed. Fiftieth, $75^{\text {th }}, 90^{\text {th }}$, and $95^{\text {th }}$ blood pressure percentiles were determined for each age grup. Children with systolic and diastolic blood pressure above $95^{\text {th }}$ percentile according to the US Second Task Force Group levels were accepted as hypertension.

Result: Accordingly, systolic hypertension was detected in 40 (4.4\%) children (12 male, 28 female), diastolic hypertension in 28 (3.1\%) children (6 male, 22 female), and both systolic and diastolic hypertension in 15 (1.6\%) children (4 male, 11 female). Systolic and diastolic hypertension proportions were $1.8 \%$ and $1.2 \%$ in the schools with high socioeconomic levels, and $2.5 \%$ and $1.8 \%$ in the schools with low socioeconomic levels, respectively. A significant relation was found between socioeconomic level of the school and systolic hypertension depending on age and sex $(p=0.031)$, but no significant relation with diastolic hypertension $(p=0.086)$.

Concluction: While a positive correlation was detected with Pearson's Correlation Test between both systolic and diastolic hypertensions and age, height, body weight, BMI, and surface area of the child in both sexes, no significant correlation was found with sex.

Key Words: Blood pressure, body weight, childhood, height, sex

\section{Giriş}

Yenidoğan döneminden itibaren her yaşta görülebilen arteryel kan basıncı yüksekliği bazı önemli hastalıkların komplikasyonu olarak karşımıza çıkabilir. Erişkin dönemdeki yüksek kan basıncı düzeylerinin erken bir göstergesi olabilir. Çocuklarda erken tanı ve tedavi açısından kan basıncı ölçümlerinin rutin muayene içinde yer alması gerekir. Amerika Birleşik Devletlerinde bu konuda görevlendirilmiş olan "Second Task Force" (STF) grubu çocuklara hiçbir şikayeti olmasa bile üç yaşından başlayarak adolesan dönemin sonuna kadar yılda en az bir kez arteriyel kan basıncı ölçümü yapılmasını önermektedir [1]. Ülkemizde rutin ölçümlerde veya bu konuda yapılan çalışmalarda, STF grubunun saptamış olduğu değerler baz alınarak değerlendirmeler yapılmaktadır. Ülkemizde farkı bölgelerde yapılan çalışmalarda Türk çocukları için de kan basıncı ortalamaları oluşturulmaya çalışılmıştır. Bu çalışmalara göre ülkemizde çocukluk çağında hipertansiyon sıkığı farkı bölgelerde \% 2,2 - 12,3 arasında değişmektedir. Kan basıncı yaş, cinsiyet, ağırlık, boy, vücut kitle indeksi (BMI) genetik ve çevresel faktörlerden etkilenebilir [2-9,10]. Değişik çalışmalarda bulunan bu farklı sonuçların bu etmenlere bağlı olarak değiştiği düşünülebilir. Koruyucu hekimlik açısından önemi vurgulanmaya çalışılan kan basıncının Kırıkkale ilinde 7-15 yaş grubu çocuklarda ortalama değerlerini saptamak ve bu değerleri etkileyen faktörleri göstermek amacıyla bu çalışma planlanmıştır.

\section{Gereç ve Yöntemler}

Araştırmamız kesitsel bir çalışma olarak planlanmıştır. Kırıkkale il merkezinde bulunan sosyoekonomik düzeyi yüksek olan iki ilköğretim okulu ile sosyoekonomik düzeyi düşük olan bir ilköğretim okulunda öğrenim gören toplam 905 öğrenci çalışma grubunu oluşturmuştur. Okul ve sınıfların öğ- renci sayısına göre her sosyoekonomik düzeyden öğrenci içerecek şekilde grup örnekleme yöntemi ile araştırma grubu oluşturulmuştur.

Her okulda arteryel kan basıncının doğru olarak ölçülmesi ve değerlendirilmesi için, öğrenci ile ölçümü yapanlar dışında kimsenin bulunmadığı sessiz ve sakin bir oda kullanılmıştır. Dinlenmiş olan çocukların kan basınçları dik oturur durumda iken, sağ kol kalp hizasında masaya konularak, üst kol uzunluğunun yaklaşık \%75'ini kaplayacak ve tam olarak saracak genişlikte manşonlar kullanılarak ölçüldü. Her çocuğun ölçümleri ikişer kez tekrarlanıp ortalamaları o çocuğun sistolik ve diyastolik kan basıncı olarak kayıt edildi. Ölçümler sabah 09-12 saatleri arasında yapıldı. Her çocuğun ikinci kez ölçümü farkı bir çocuk doktoru tarafından, önceki değeri bilinmeden yapıldı. Her yaş grubundaki kız ve erkek çocuklar için sistolik ve diyastolik kan basıncı değerlerinin 50.- 75.- 90. ve 95. persantilleri hesaplandı. Her çocuğun genel fizik muayeneleri ve antropometrik ölçümleri (Boy, vücut ağırlığı, BMI ) üçüncü bir çocuk doktoru tarafından kaydedildi.

Amerika Birleşik Devletleri Second Task Force grubunca hazırlanan kan basıncı persantil eğrilerine göre, kan basıncı yaşa ve cinsiyete göre 95. persantil üzerinde olanlar hipertansif kabul edilerek ileri inceleme için aileleri ile birlikte hastanemize çağrıldı.

Kan basıncı ile yaş, boy, vücut ağırlığı, yüzey alanı arasındaki ilişkinin değerlendirilmesinde SPSS programında Pearson Korelasyon Analizi kullanıldı ve $p<0,05$ 'in altı anlamlılık sınırı olarak kabul edildi.

\section{Bulgular}

Çalışma grubunu oluşturan 905 öğrencinin 451 erkek (\%49), 454 kız (\%51) ve yaş ortalaması 10,98 2 2,2 yı (min 7-max 15 yaş) idi. Yaş gruplarına göre ortalama sistolik ve diyastolik kan basıncı değerleri Tablo 1'de, gösterilmiştir. 
Tablo 1: Kırıkkale ili 7-15 yaş grubu çocukların yaşa göre sistolik ve diyastolik kan basıncı değerleri (ortalama \pm SD)

\begin{tabular}{|c|c|c|c|}
\hline Yaş & $\mathbf{n}$ & $\begin{array}{c}\text { Sistolik kan basıncı } \\
(\mathbf{m m H g})\end{array}$ & $\begin{array}{c}\text { Diyastolik kan basıncı } \\
(\mathbf{m m H g})\end{array}$ \\
\hline 7 & 74 & $101,8 \pm 9,2$ & $64,6 \pm 7,9$ \\
\hline 8 & 84 & $100,4 \pm 9,1$ & $62 \pm 8,9$ \\
\hline 9 & 112 & $99,5 \pm 9,6$ & $61,6 \pm 8,3$ \\
\hline 10 & 88 & $100,8 \pm 9,7$ & $63,3 \pm 6,8$ \\
\hline 11 & 116 & $104 \pm 9,5$ & $64,6 \pm 8,3$ \\
\hline 12 & 120 & $104,8 \pm 11$ & $64 \pm 7,2$ \\
\hline 13 & 138 & $107 \pm 9,7$ & $66,1 \pm 7,1$ \\
\hline 14 & 127 & $108,3 \pm 11,1$ & $66 \pm 7,5$ \\
\hline 15 & 46 & $111,5 \pm 13$ & $67,6 \pm 8,7$ \\
\hline TOPLAM & & 905 & \\
\hline
\end{tabular}

Çocukların kan basıncı değerleri Second Task Force ile karşılaştırıldlğında, 40 çocukta $(\% 4,4)$ sistolik hipertansiyon (12 erkek, 28 kIz), 28 çocukta $(\% 3,1)$ diyastolik hipertansiyon (6 erkek, 22 kIz), 15 çocukta $(\% 1,6)$ ise hem sistolik hem de diyastolik hipertansiyon (4 erkek, 11 kIz) saptanmıştır.

Okulların sosyoekonomik durumlarına göre her yaş grubunda ortalama sistolik ve diyastolik kan basıncı değerleri Tablo II'de gösterilmiştir. Sosyoekonomik düzeyi yüksek okullarda sistolik hipertansiyon oranı $\% 1,8$, diyastolik hipertansiyon oranı \%1,2, sosyoekonomik düzeyi düşük okulda sistolik hipertansiyon oranı \%2,5, diyastolik hipertansiyon oranı \%1,8 bulunmuştur.

Her iki cinsiyette de hem sistolik hem de diyastolik arteryel kan basıncı

Tablo 2: Kırıkkale ili 7-15 yaş grubu çocukların sosyoekonomik durumuna göre kan basıncı ortalamaları

\begin{tabular}{|c|c|c|c|c|c|c|}
\hline \multirow[b]{2}{*}{ Yaş } & \multicolumn{3}{|c|}{ Sosyoekonomik düzeyi yüksek okullar } & \multicolumn{3}{|c|}{ Sosyoekonomik düzeyi düşük okullar } \\
\hline & $\begin{array}{l}\text { Sistolik KB } \\
\text { ortalama } \pm S D\end{array}$ & $\begin{array}{l}\text { Diyastolik KB } \\
\text { ortalama } \pm S D\end{array}$ & $\mathrm{n}$ & $\begin{array}{c}\text { Sistolik KB } \\
\text { ortalama } \pm \text { SD }\end{array}$ & $\begin{array}{l}\text { Diyastolik KB } \\
\text { ortalama } \pm \text { SD }\end{array}$ & $\mathrm{n}$ \\
\hline 7 yaş & $106,77 \pm 8,32$ & $66,12 \pm 8,82$ & 31 & $97,76 \pm 8,02$ & $63,42 \pm 6,98$ & 38 \\
\hline 8 yaş & $102,69 \pm 10,7$ & $64,23 \pm 10,64$ & 26 & $99,47 \pm 8,27$ & $61,05 \pm 6,73$ & 57 \\
\hline 9 yaş & $98,52 \pm 9,12$ & $60,80 \pm 8,13$ & 68 & $101,04 \pm 10,31$ & $62,91 \pm 8,49$ & 48 \\
\hline 10 yaş & $99,01 \pm 8,93$ & $62,67 \pm 7,00$ & 56 & $103,60 \pm 10,31$ & $64,18 \pm 6,63$ & 43 \\
\hline 11 yaş & $101,79 \pm 9,64$ & $63,80 \pm 8,62$ & 67 & $106,86 \pm 8,71$ & $65,68 \pm 7,93$ & 51 \\
\hline 12 yaş & $104,89 \pm 11,03$ & $64,58 \pm 8,04$ & 48 & $104,76 \pm 11,2$ & $63,65 \pm 6,61$ & 63 \\
\hline 13 yaş & $107,84 \pm 10,06$ & $67,25 \pm 6,69$ & 93 & $105,55 \pm 9,14$ & $64,16 \pm 7,57$ & 54 \\
\hline 14 yaş & $109,93 \pm 12,20$ & $67,56 \pm 7,36$ & 74 & $106,10 \pm 8,64$ & $63,90 \pm 7,44$ & 50 \\
\hline 15 yaş & $115,01 \pm 17,7$ & $71,42 \pm 11,16$ & 14 & $108,88 \pm 7,18$ & $64,72 \pm 4,99$ & 22 \\
\hline Toplam & & & 477 & & & 428 \\
\hline
\end{tabular}

değerleri ile yaş, boy, vücut ağırlığı, vücut kitle indeksi arasında Pearson Korelasyon Testi ile pozitif ilişki saptanmıştır (Tablo 3).

Araştırma grubumuzda yaş gruplarında ortalama kan basıncı değerleri erkek ve kız çocuklarında birbirinden farklı olup kızlarda diyastolik kan basın-

Tablo 3: Kırıkkale ili 7-15 yaş grubu çocuklarda sistolik ve diyastolik kan basıncı değerleri ile yaş, boy, ağırlık, ve vücut kitle indeksi arasındaki ilişki

\begin{tabular}{|c|c|c|c|c|}
\hline & \multicolumn{2}{|c|}{ Sistolik Kan Basıncı (mmHg) } & \multicolumn{2}{|c|}{ Diyastolik Kan basıncı (mmHg) } \\
\hline & Korelasyon katsayısı (r) & P değeri & Korelasyon katsayısı (r) & p değeri \\
\hline Yaş (yll) & 0,2964 & $p<0,001$ & 0,1758 & $p<0,001$ \\
\hline Boy (cm) & 0,3544 & $p<0,001$ & 0,2717 & $p<0,001$ \\
\hline Ağırlık (kg) & 0,3906 & $p<0,001$ & 0,3116 & $p<0,001$ \\
\hline $\mathrm{BMl}\left(\mathrm{kg} / \mathrm{m}^{2}\right)$ & 0,1494 & $p<0,001$ & 0,1016 & $p<0,001$ \\
\hline Yüzey alanı(m²) & 0,3819 & $p<0,001$ & 0,2980 & $p<0,001$ \\
\hline
\end{tabular}


$\mathrm{Cl}$, erkeklerde ise sistolik kan basıncı ortalama değerleri diğer cinse göre yüksek bulunmasına rağmen sonuçlar istatistiksel olarak anlamlı değildir (Tablo 4) ( $p>0.05)$.

\section{Tartışma}

Arteryel kan basıncı ölçümünün çocukluktan başlayarak standartlara uygun bir biçimde, yaşa ve cinsiyete göre değerlendirilmesi ve izlenmesi, hipertansiyon, arterioskleroz ve kalp damar hastalıkları riskini azaltabilecek bir koruyucu sağlık hizmetidir [6].

Tablo 4: Kırıkkale ili 7-15 yaş grubu çocuklarda sistolik ve diyastolik kan basıncı değerleri ile yaş, boy, ağırlık, BMI arasındaki ilişki

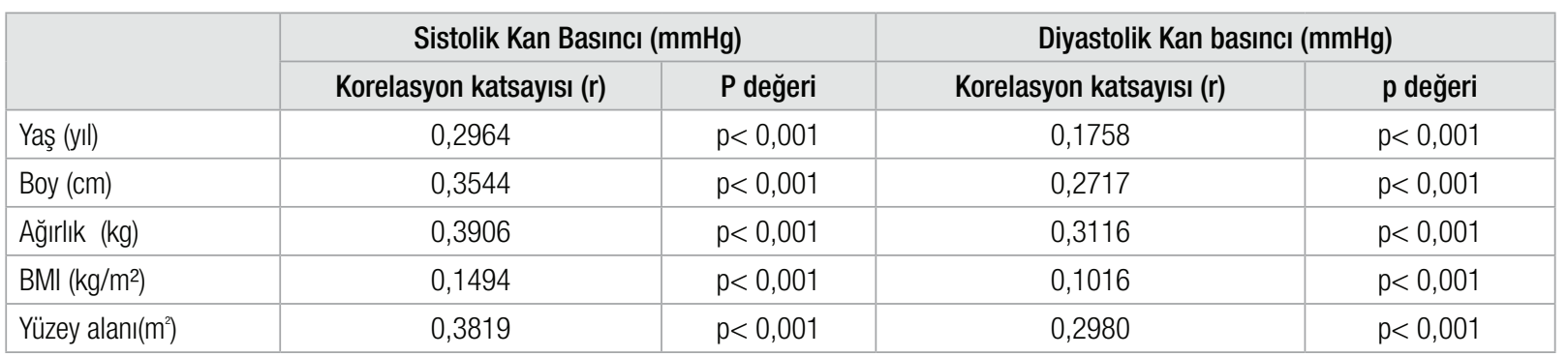

Çocukluk döneminde kan basıncı ölçümlerinin önemi, birçok araştırmacı tarafından gösterilmiştir. Lauer ve Clarke [11], çocuklukta bir veya daha fazla ölçümde sistolik veya diyastolik kan basıncı yüksekliği bulunan kişilerin yetişkin olduklarında kan basıncı yüksekliği açısından 2-2.5 kat daha fazla risk taşıdığını göstermişlerdir. Gillman ve ark. [12] da kan basıncının belirlenmesinde farklı zamanlarda tekrarlanan ölçümlerin daha doğru sonuç verdiğini bildirmiş ve relatif olarak yüksek kan basıncı bulunan çocuklarda ölçümlerin tekrarlanmasını önermişılerdir. Çocukta oluşabilecek anksiyete durumu kan basıncını yükseltebildiğinden ölçümlerin anksiyete durumu en aza indirilerek yapılması önerilmektedir [2,8]. Çalışmamızda da çocukların anlayabileceği bir dille çalışma hakkında bilgi verilmiş ve ölçümlerin çocuklar sakin ve dinlenmiş durumunda iken yapılması ile mevcut anksiyete durumunun en aza indirgenmesine çalışılmıştır. Çaışmamızda okulda yaptığımı kan basıncı ölçümünün çocuklarda stress oluşturabileceği düşünülmüş ve çocukların yanlış hipertansiyon tanısı almalarını önlemek için hem kan basıncı ölçümlerinin tekrarlanması hem de hipertansiyonun olası nedenlerinin araştırıması amacı ile hipertansif olarak saptanan çocuklar hastaneye davet edilmiştir.

Amerika Birleşik Devletleri Second Task Force Grubu yaș ve cinse göre 90-95. persantillerde olan sistolik ve diyastolik kan basıncını "yüksek normal kan basıncı" olarak tanımlamış ve 95. persantil üzerinde olan sistolik veya diyastolik kan basıncını ise "yüksek kan basıncı" olarak kabul etmiştir [2]. Biz de çalışmamızda hipertansiyon sınırını STF grubunun yaş ve cinse göre 95. persantil değerlerinin üzeri olarak aldık.

Dünyanın pek çok ülkesinde çocukluk çağında kan basıncı normogramlarını saptamak amacıyla çok sayıda çalışma yapıımıştır. Yapılan çalışmalarda farklı yöntemlerin kullanılmış olması, grup sayılarının farkı olması, manşon boyutlarının tam belirlenmemiş olmasına ek olarak olası genetik ve çevresel faktörlerin de etkisi ile birbirinden farklı sonuçlar elde edilmiştir [2]. Çocukluk çağında hipertansiyon sıklığının \%0,86-12,3 arasında değiştiği bildirilmektedir [10]. Ülkemizde de farkı bölgelerde yapılan çaışmalarda Türk çocukları için kan basıncı normogramları oluşturulmaya çalışımıştır (Tablo 4). Bu çalışmalarda verilen hipertansiyon sıklıkları birbirinden oldukça farkııdır. İspanya'da yapılan bir çalışmada 19 yaş altı çocuklarda sistolik kan basıncı için hipertansiyon sıkı̆̆ı \%8 ve diyastolik kan basıncı için \%9 olarak bildirilmiştir [13].

Bizim çalışmamızda 7-15 yaş okul çağı çocuklarının kan basıncı değerleri STF ile karşılaştırıldığında; 40 çocukta $(\% 4,4)$ sistolik hipertansiyon, 28 $(\% 3,1)$ çocukta diyastolik hipertansiyon, $15(\% 1,6)$ çocukta ise hem sistolik hem de diyastolik hipertansiyon saptanmıştır. Çalışmamız sonuçları ülkemizde ve dünyada yapılan çalışmalardan çok farklı değildir.

Tablo 5: Ülkemizde farkı yaş gruplarında hipertansiyon sıkığı

\begin{tabular}{|lclcl|}
\hline Araştırıcı & Yıl & Yer & Yaş & HT sıkı̆̆ı \\
\hline Elevli ve ark. [30] & 1991 & Diyarbakır & $6-12$ & $\% 2,2$ \\
\hline Çalı ve ark. [31) & 1985 & Antalya & $13-20$ & $\% 5,8$ \\
\hline Coşkun ve ark. [32] & 1997 & Gaziantep & $7-15$ & $\% 12,3$ \\
\hline Koç ve ark. [10] & 1999 & Şanlıurfa & $6-16$ & $\% 0,86$ \\
\hline Çalışmamız & 2008 & Kırıkkale & $7-16$ & $\% 7,5$ \\
\hline
\end{tabular}


Çocuk ve erişkinlerde kan basıncı değerleri üzerine yapılan epidemiyolojik çalışmalar, çocukluk döneminde her iki cinsiyette de sistolik basınçta daha fazla olmak üzere sistolik ve diyastolik kan basıncı ortalama değerIerinin yaş ile birlikte arttığını göstermektedir [2,3,5,6,14,15]. Kan basıncı değerlerinin sadece yaş ile değil vücut ağırlığı ve boy ile de ilişkili olduğu bildirilmektedir [5-7,12]. Duarte ve ark.nın [16] Portekiz'de yaptıkları çalışmada yaşın kan basıncına mutlak etki eden faktör olduğu ve çoklu regresyon analizlerinde vücut ağırlığı ve yaşın her iki cinste de anlamlı değişimlere neden olduğu gösterilmiştir. Bizim çalışmamızda da kız ve erkek çocuklarda hem sistolik hem de diyastolik arteryel kan basıncı değerleri ile yaş, vücut ağırlığı ve boy arasında pozitif ilişki saptanmıştır.

Bazı araştırıcılar vücut ağırlığındaki artış ile, Kafalı ve ark. [17] ise boydaki artış ile kan basıncı artışı arasında bir ilişki olduğunu bildirmişlerdir. Koç ve ark.nın [10] çalışmasında ise, sistolik kan basıncında boy artışı ile, diyastolik kan basıncında ise ağırık artışı ile pozitif korelasyon bulunmustur. Bizim çalışmamızda ise, özellikle boy ile diyastolik kan basıncı arasında, vücut ağırlığı ile sistolik kan basıncı arasında anlamlı ilişki saptanmıştır. Ağırlık ve boy değerlerinin artışına paralel olarak total kan volümünün artışı kan basıncında yükselmeye neden oluyor diye düşünülebilir [18].

Çalışmamızda BMı ve yüzey alanı ile sistolik ve diyastolik kan basıncı artışı arasında da anlamlı ilişki saptanmıştır $(p<0,001)$. Çocuklar ve yetişkinler üzerinde yapılan farklı çalışmalarda obesite ile kan basıncı artışı arasında anlamlı ilişki olduğu gösterilmiştir [4,19,20]. Felea ve ark. [21], Romen çocuklarda yaş ve genetik faktörlerin etkisini ortadan kaldırdıklarında bile obesitenin önemli bir risk faktörü olduğunu göstermişlerdir. Bizim çalışmamızda BMI'ne göre 38 çocuğun obes olduğu ve bu çocukların 4'ünde (\%10) hem sistolik hemde diyastolik kan basıncı yüksekliği saptandı ki bu değer toplam grubun $(\% 7,5)$ hipertansiyon oranına göre yüksektir.

Araştırma grubumuzda her yaş grubunda ortalama kan basıncı değerlerinin erkek ve kız çocuklarında birbirinden farklı olduğu saptanmıştır. Kızlarda diyastolik kan basıncı, erkeklerde ise sistolik kan basıncı değerleri karşı cinse göre yüksek bulunmasına rağmen bu sonuçlar istatistiksel olarak anlamlı değildir $(p>0,05)$. Cinsiyet ile kan basıncı ilişkisi birçok araştırmacı tarafından farkı şekilde saptanmıştır. Bazı çalışmalarda, ortalama kan basıncı değerleri farklı olduğunu [6,22-25], bazılarında erkeklerde [2325], bir kısmında ise kızlarda daha yüksek olduğu gösterilmiştir [26]. Bizim çalışmamıza benzer şekilde adolesan çağa kadar cinsiyet ile ortalama kan basıncı değerleri arasında belirgin bir fark olmadığını ancak adolesan döneminden sonra değiştiğini bildiren araştırmacılar da vardır [27]. Kıyak ve ark. [5], 6-11 yaş grubunda kızların sistolik ve diyastolik kan basıncı ortalamalarının erkeklerde yüksek olduğunu bulmuş, Tümerdem ve ark. [6] ise, 7-12 yaş grubunda erkek çocukların sistolik ve diyastolik kan basıncı ortalamalarının kızlarınkinden daha yüksek olduğunu bildirmişlerdir. Tümer ve ark. [28] yapmış oldukları çalışmada sistolik ve diyastolik kan basınçları açısından cinsiyet ve sosyoekonomik duruma göre belirgin bir farklıık bulunmamış olmasına rağmen kan basıncı değerlerinin boy ve vücut ağırlığı ile doğru orantılı olarak artı̆̆ı saptanmıştır. Gakova ve ark.
[29] Rusya'da kuzeyde soğuk bölgelerde yaşayan çocuklarda hipertansiyon sıklığını ülke geneline göre daha yüksek bulmuş $(\% 12,7)$ ve çalışmamıza benzer şekilde erkeklerde kızlara göre hipertansiyon oranının daha yüksek olduğunu göstermiş̧lerdir (erkeklerde \%14,1 ve kızlarda \%11,6) .

Illimiz çocuklarında, erkeklerde sistolik ve diyastolik kan basıncı değerlerinin STF değerleri ile paralellik gösterdiği ancak kızlarda sistolik kan basıncı değerlerinin STF değerlerine göre anlamlı olarak yüksek olduğu gösterilmiştir (Şekil 1-4). Sosyoekonomik düzeyi yüksek okullarda sistolik hipertansiyon oranı \%1,8, diyastolik hipertansiyon oranı \%1,2, sosyoekonomik düzeyi düşük okullarda sistolik hipertansiyon oranı $\% 2,5$, diyastolik hipertansiyon oranı \%1,8 bulunmuştur. Okulların sosyoekonomik durumuna göre, yaş ve cinse bağlı olarak sistolik kan basıncı değerleri arasında anlamlı bir ilişki bulunurken $(p=0,031)$, diyastolik kan basıncı arasında anlamlı bir ilişki $(p=0,086)$ saptanamamıştır. Sonuçlardaki değişikliklerin sosyoekonomik, genetik ve çevresel faktörlerdeki farklııklara bağlı olduğunu düşünmekteyiz. Ayrıca erkeklerin vücut kitle indeksinin kızlara göre fazla olması ile birlikte erkek ve kızlardaki hormonal farkııı̆ın da bu değişiklikte etkili olabileceğini düşünmekteyiz.

Sonuç olarak bu çalışma ile, Kırıkkale ili çocukları için ortalama kan basıncı değerleri ve standart sapmaları belirlenmiş, kan basıncı değerlerinin, yaş, boy, ağırlık, BMI ile anlamlı bir artış gösterdiği, cinsiyet ile kan basıncı arasında anlamlı bir ilişki bulunmadığı gösterilmiştir. Ayrıca çalışmamız sonuçları ile hipertansiyonun erken tanısı için çocuklukta yapılan düzenli kan basıncı ölçümlerinin önemi bir kez daha vurgulanmıştır. Çalışmamız araştırma grubu her ne kadar Kırıkkale ilini tam yansıtmasa da geniş örneklem grubu içermesi ve farklı etken faktörlerin göz önünde bulundurulmuş olması nedeniyle, araştırmamız sonuçlarının hasta değerlendirilmesinde göz önünde bulundurulmasını önerebiliriz. Ancak Kırıkkale ili kan basıncı normogramların çıkarılması için sonuçlarını sunduğumuz araştırmamız ön çalışma gibi düşünülüp daha geniş örneklem grubu içeren ve daha çok etken faktörün göz önünde bulundurulduğu ileri bir çalışmanın planlanması düşünülebilir.

Araştırmada hipertansif olduğu saptanan 68 çocuk izleme alınmıştır. Düzenli kontrolleri yapılmaktadır. İleri bir dönemde bu çocuklara ait bulgular başka bir çalışma ile değerlendirilecektir.

\section{Kaynaklar}

1. Pickering TG. Principles and techniques of blood pressure measurement. Cardiol Clin 2002;20: 207-23.

2. Report of the Second Task Force on Blood Pressure Control in Children1987. Pediatrics 1987;79:1-25.

3. Tsioufis C, Kyvelou S, Tsiachris D at al. Relation between physical activity and blood pressure levels in young Greek adolescents: the Leontio Lyceum Study. Eur J Public Health 2011;21:63-8.

4. Gillman MW, Ellison RC. Childhood prevention of essential hypertension. Pediatr Clin North Am 1993;40:179-94.

5. Candan $\mathrm{C}$, Çalışkan S. Çocukluk çağında hipertansiyona yaklaşım. Türk Pediatri Arşivi 2005;40:15-22. 
6. Tümerdem Y, Ayhan B, Özçelik H, Tümerdem B, Alnıgeniş E. IIlkokul çocuklarında arteryel kan basıncı değerlendirilmesi.Çocuk Sağlığı ve Hastalıkları Dergisi 1993;36:353-61.

7. Spagnolo A, Giussani M, Ambruzzi AM at al Focus on prevention, diagnosis and treatment of hypertension in children and adolescents. Ital J Pediatr 2013;19;39:20.

8. Akgun C, Dogan M, Akbayram S at al. The incidence of asymptomatic hypertension in school children. J Nippon Med Sch 2010;77:160-5.

9. Janssen I, Leblanc AG. Systematic review of the health benefits of physical activity and fitness in school-aged childrenand youth. Int J Behav Nutr Phys Act 2010;11;7:40

10. Koç $A$, Kösecik M, Ataş $A$, Erel Ö, Tatlı MM. Şanlıurfa'da 6-16 yaş grubu çocuklarda hipertansiyon sıklığı ve etiyolojisi araşııması. Çocuk Sağlığı ve Hastalıkları Dergisi 1999;42:513-21.

11. Lauer RM, Clarke WR. Childhood risk factors for high adult blood pressure: the Muscatine Study. Pediatrics 1989;84:633-41.

12. Gillman MW, Cook NR, Rosner B, et al Identifying children at high risk for the development of essential hypertension. J Pediatr 1993;122:837-46.

13. Cervantes J, Acoltzin C, Aguayo A. Diagnosis and prevalence of arterial hypertension in persons under 19 years of age in the city of Colima. Salud Publica Mex 2000;42:529-32.

14. Ogedegbe G, Pickering T. Principles and techniques of blood pressure measurement. Cardiol Clin 2010;28:571-86.

15. Feber J, Ahmed M. Hypertension in children: new trends and challenges. Clin Sci (Lond) 2010;119:151-61.

16. Duarte JA, Guerra SC, Ribeiro JC, Mota RC. Blood pressure in pediatric years (8-13 years old) in the Oporto region. Rev Port Cardiol 2000;19: 809-20.

17. Kafalı $G$, Toksoy H,Cevit 0 . Blood pressure measurement in children aged 7-15 years in Sivas region-Turkey. J Trop Pediatr 1997;43:243-8.

18. Voors A.W, Webber I.S. Fredericks R.R, et. Al. Body weight and body mass as determinants of basal blood pressure in children. The Bogalusa Heart Study, Am J Epidemiol 1977;106: 101.

19. Lurbe $E$, Alvarez $V$, Liao $Y$, et al The impact of obesity and body fat distribution on ambulatory blood pressure in children and adolescents. Am $J$ Hypertens 1998;11: 418-24.
20. Figueroa-Colon R, Franklin FA, Lee JY, Aldridge R, Alexsander L. Prevalance of obesity with increased blood pressure in elementary school-aged children. South Med J 1997;90:806-13.

21. Felea D, Matasaru S, Dimitriu AG. Risk factors in child and adolescent with systemic hypertension. Rev Med Chir Soc Med Nat lasi 2000;104:71-6.

22. Steinfeld L, Sphygmomanometry in Pediatric Patients. J Pediatr 1978;92:934.

23. Sweet M. Blood Pressure in infancy. Am Heart J 1977; 94: 399.

24. Sweet M , Mayers P, Shinebourne E. A. Value of Repeated Blood Pressure Measurements in Children. The Brompton Study. Br J Med 1980; 28: 1567.

25. Voors A W, Webber IS, Fredericks R R. Studies of Blood Pressure in Children ages 5 to 14 years, in a Total Biracial Community. The Bogalusa Heart Study. Circulation.1976;54: 319.

26. Goldring D. Blood Pressure in High School Population. J Pediatr 1977;91: 881.

27. Gökçay E, Özcan 0, 2-14 yaş grubu çocuklarda arteryel kan basıncı normal değerlerinin saptanması, yaş, cins, ağılık ve boyla ilişkisi. GATA Bülteni 1991;33:749-60.

28. Tümer N, Yalçınkaya F, İnce E, Ekim M, Köse K, Çakar N, Kara N, Özkaya N, Ensari C, Önder S. Blood pressure nomograms for children and adolescents in Turkey. Pediatr Nephrol 1999;13:438-43.

29. Gakova El, Aseeva SI. Arterial pressure mean values and distribution, and relation to duration of residence in the North in school children living in the north of Tumen region. Ter Arkh 2001; 73:21-4.

30. Elevli M, Yakut I, Devecioğlu C, Günbey S, Taş MA. Diyarbakır il merkezinde iki ilkokulda yapılan arteryel hipertansiyon araştırması. Dicle Tıp Bülteni 1991;18:88-92.

31. Çalı Ş, Bircan İ, Ertuğ H. Antalya il merkezindeki liselerde arteryel hipertansiyon araştırması. Akdeniz Üniversitesi Tıp Fakültesi Dergisi 1985;2: 351-6.

32. Coşkun Y, Bayraktaroğlu Z.Coronary risk factörs in Turkısh school children report of a pilot study.Acta Paediatr 1997;86:187-91 